\title{
Influence of surgery for peptic ulcer on pneumoconiosis and tuberculosis
}

\author{
T. J. G. PHILLIPS \\ Pneumoconiosis Medical Panel, Arden House, Regent Farm Road, \\ Gosforth, Newcastle upon Tyne
}

\begin{abstract}
Phillips, T. J. G. (1970). Brit. J. industr. Med., 27, 245-249. Influence of surgery for peptic ulcer on pneumoconiosis and tuberculosis. Simple pneumoconiosis in coal miners who have had a partial gastrectomy has often been observed at this Panel to lead to progressive massive fibrosis (PMF). A series comprising 224 men, who had had either a partial gastrectomy, a gastro-enterostomy with or without vagotomy, or a simple closure of a perforated peptic ulcer, was collected over a period of four years. A control series of 220 men who had originally presented with simple pneumoconiosis at least 10 years previously was also studied.

Active pulmonary tuberculosis developed in 13 of 106 men $(12.2 \%)$ following partial gastrectomy compared with 2 of 68 men $(2.9 \%)$ in the gastro-enterostomy group, 1 of 50 men $(2 \%)$ in the perforated peptic ulcer group, and 4 of 220 men $(1.8 \%)$ in the control series. Of those who had had a partial gastrectomy, $48.6 \%$ progressed to massive fibrosis subsequently, compared with $16.5 \%$ in the gastro-enterostomy group, $22 \%$ in the perforated peptic ulcer group, and $37.9 \%$ in the control series. Possible reasons for these differences are discussed as well as the current theories of the aetiology of PMF.

In view of the increased incidence of tuberculosis and possibly of massive fibrosis in those men who have had a partial gastrectomy in this series, it is recommended that this operation should be avoided in the treatment of peptic ulcer in coal miners with pneumoconiosis.
\end{abstract}

Following a partial gastrectomy for peptic ulcer, simple pneumoconiosis in coal-workers has often been observed at this Panel to lead to progressive massive fibrosis (PMF). The course of pneumoconiosis in those men who have had surgery for peptic ulcer, as well as in a control series presenting with simple pneumoconiosis, was therefore studied.

\section{Material and methods}

The majority of claimants certified as suffering from pneumoconiosis are kept under observation at Pneumoconiosis Panels in this country for the rest of their lives. They are invited to attend for review of their disability assessment (usually at intervals of one to three years) and are subjected to a full clinical and radiological examination on each occasion. Thus adequate records, which may extend as far back as 20 years, are available for study. The majority of men who attend this Panel come from the counties of Durham and Northumberland.

A series comprising 224 men, who had had surgery for peptic ulceration and had been observed for at least five years after their operation, was collected over a period of four years. These were subdivided into three groups according to the nature of their surgical treatment (see Results). In addition, a control series comprising 220 men, who had originally presented with simple pneumoconiosis at least 10 years previously, was also studied.

All radiographs had been categorized by at least two members of this Panel. Simple pneumoconiosis was classified as category 1,2 , or 3 (ILO, 1959), depending on the extent and density of opacities whose greatest diameter was less than $1 \mathrm{~cm}$ or as PMF when the opacities had a greatest diameter of at least $1 \mathrm{~cm}$. All these men had worked under approved dust conditions (Bedford and Warner, 1943; National Coal Board,1965) or had left the industry since certification. 


\section{Results}

\section{Group I Partial gastrectomy}

This group, of average age 60.8 years, consisted of 106 men who had had a partial gastrectomy and comprised:

(a) 30 men who were first seen with simple pneumoconiosis which showed no progression over an average period of observation of $10 \cdot 1$ years;

(b) 36 men who were first seen with simple pneumoconiosis which subsequently progressed to PMF. They had been observed for an average period of 8.5 years and massive fibrosis developed at an average period of $\mathbf{7 \cdot 2}$ years after operation;

(c) 27 men who presented with massive fibrosis, which progressed subsequently over an average period of observation of $9 \cdot 6$ years; and

(d) 13 men who developed active pulmonary tuberculosis with a positive sputum some time after their operation. Eight of these men had originally presented with category 2 simple pneumoconiosis, while the remaining five had presented with PMF.

\section{Group II Gastro-enterostomy}

This group consisted of 68 men, whose average age was 61 years, who had had a gastro-enterostomy, with or without a vagotomy (approximately half of the men had had a vagotomy with their gastroenterostomy, but this apparently did not influence the progression of the pneumoconiosis):

(a) 49 men were first seen with simple pneumoconiosis, which showed no progression over an average period of observation of 10.4 years;

(b) 10 men were first seen with simple pneumoconiosis, which subsequently progressed to massive fibrosis. They had been observed for an average period of 8.6 years, and PMF developed at an average period of $5 \cdot 8$ years after operation;

(c) 5 men presented with massive fibrosis which progressed subsequently over an average period of observation of $8 \cdot 1$ years;

(d) 2 men, who had presented with category 2 simple pneumoconiosis, developed active pulmonary tuberculosis, one at 6 and the other at 8 years after operation;

(e) 2 men presented with PMF which remained unchanged over an average period of observation of 6.5 years.

\section{Group III Closure of perforated peptic ulcer}

This group consisted of 50 men, whose average age was 61.8 years, who had had simple closure of a perforated peptic ulcer:

(a) 32 men presented with simple pneumoconiosis which showed no progression over an average period of observation of 8.8 years; (b) 9 men presented with simple pneumoconiosis, which subsequently progressed to PMF. They had been observed for an average period of 10.2 years, and PMF developed at an average period of 6.2 years after operation;

(c) 7 men presented with massive fibrosis, which progressed subsequently over an average period of observation of $7 \cdot 1$ years.

(d) 1 man presented with massive fibrosis which showed no apparent change over the next 10 years; and

(e) 1 man presented with massive fibrosis two years before operation, and developed pulmonary tuberculosis one year after his operation.

Fate of men presenting with simple pneumoconiosis Of the 224 men comprising this series, 176 presented with simple pneumoconiosis of categories 2 or 3 (Table 1). As there were only 28 of the latter, it was not felt that any separate conclusions could be drawn about these, and both categories are considered together. Seventy-four of these men had had a partial gastrectomy, and it was found that pneumoconiosis in 30 of them $(40.6 \%)$ remained simple in type, progressed to PMF in $36(48.6 \%)$, while active pulmonary tuberculosis occurred as a complication in $8(10.8 \%)$. There were 61 men with simple pneumoconiosis who had had a gastroenterostomy with or without a vagotomy, and the pneumoconiosis remained simple in type in 49 of these men $(80.2 \%)$ and progressed to PMF in 10 $(16.5 \%)$, while active pulmonary tuberculosis occurred in the remaining $2(3.3 \%)$. The remaining 41 men had had a perforated peptic ulcer and in these the pneumoconiosis remained simple in 32 $(78 \%)$ and progressed to PMF in the remaining 9 $(22 \%)$.

\section{Control series}

This comprised 220 men whose average age was 60.8 years and who were selected at random from those who had presented at this Panel at least 10 years previously with simple pneumoconiosis (196 with category 2 and 24 with category 3 ).

They had been under observation for an average period of 13.7 years. Of these men, pneumoconiosis remained simple in type in $140(60.3 \%)$ (including 15 with category 3), while progression to PMF occurred in 76 men $(37.9 \%$ ) (of whom 9 had had category 3 pneumoconiosis). Active pulmonary tuberculosis developed in the remaining 4 men $(1.8 \%)$ at an average period of four years after certification, all having had category 2 pneumoconiosis initially. (Table 2 shows the year of occurrence of PMF in the period observed.)

There was no great difference between the dates on which observation began in the various groups. 
TABLE 1

\section{RESULTS}

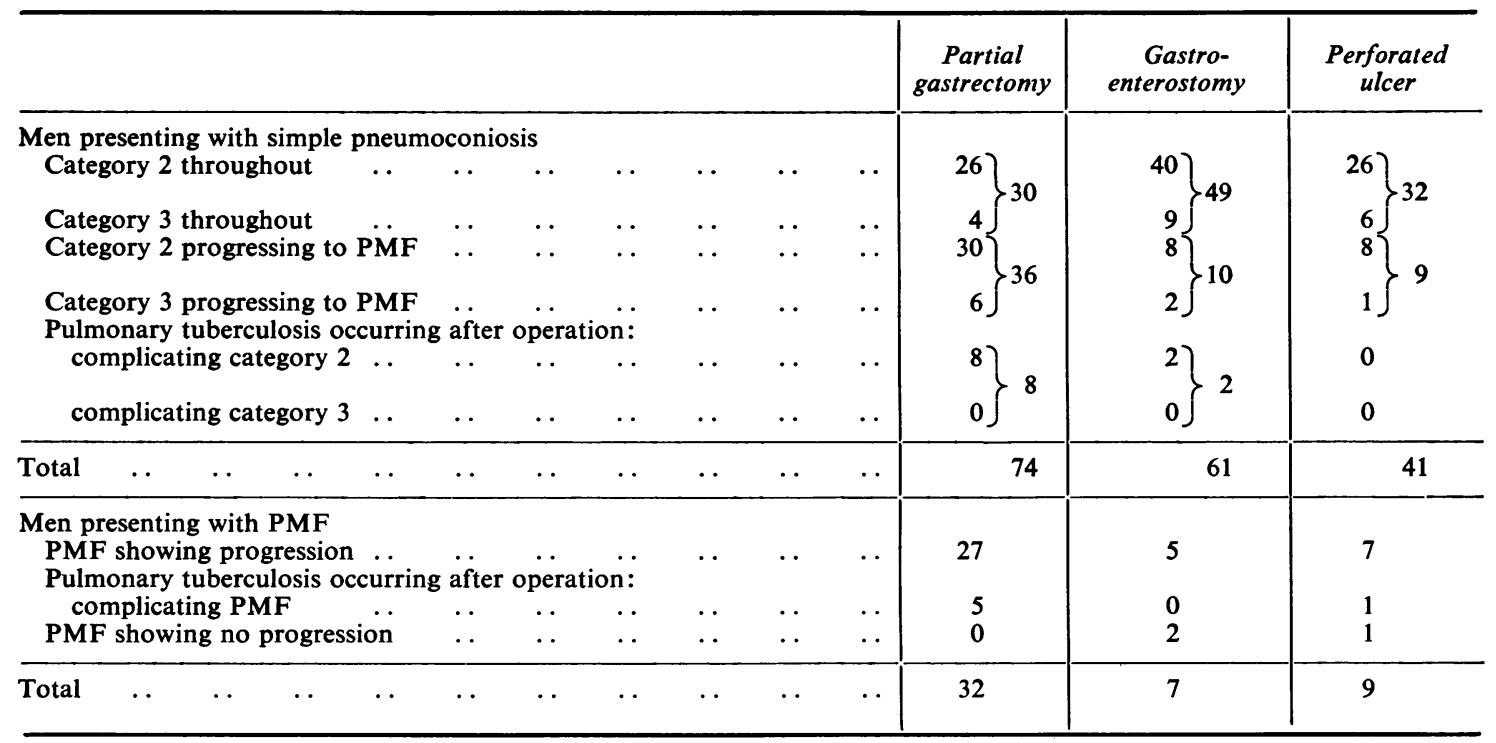

\section{Discussion}

Two noteworthy features emerge from this study. The first is the high proportion of men who developed pulmonary tuberculosis following partial gastrectomy. Thus 13 out of 106 men $(12 \cdot 2 \%)$ who had had a partial gastrectomy subsequently developed tuberculosis, compared with 1 of 50 men $(2 \%)$ who had had a perforated peptic ulcer, 2 of 68 men $(2.9 \%)$ who had had a gastroenterostomy, and 4 of $220(1.8 \%)$ of the control series. Many workers have commented on the increased incidence of pulmonary tuberculosis following partial gastrectomy (Pulvertaft, 1964; Levij and La Fuente, 1963; Anderson, Gunn, and Watt, 1955; Pearson, 1954; Balint, 1958; Thorn, Brookes, and Waterhouse, 1956; Allison, 1955). Warthin (1953) believed that the most important reason for this is a state of under-nutrition, produced by peptic ulceration and perpetuated indefinitely by a partial gastrectomy.

The second feature is the difference in the fate of men in the various groups who presented with simple pneumoconiosis. Of those who had had a partial gastrectomy $48.6 \%$ progressed to PMF, compared with $16.5 \%$ of those who had had a gastro-enterostomy, $22 \%$ of those who had had a perforated peptic ulcer, and $37.9 \%$ of those in the control series. The period that these men were observed is of importance, as a high attack rate could be due to a longer period of observation. It is essential that the periods of observation of the men whose simple pneumoconiosis did not progress to PMF be compared in the various groups (comparison of the periods of observation of those who developed PMF is not so important, as any differences here would not affect the attack rate). The average periods

TABLE 2

Year of Development of PMF following Presentation with Simple Pneumoconiosis in 76 Men of Control Series

\begin{tabular}{c|c|c|c|c|c|c|c|c|c}
\hline & \multicolumn{7}{|c}{ Year of development of $P M F$ during observation } \\
\cline { 2 - 8 } & 1 & 2 & 3 & 4 & 5 & 6 & 7 & 8 & Subsequent \\
\hline No. of men & $\begin{array}{c}18 \\
(23 \cdot 6 \%)\end{array}$ & $\begin{array}{c}16 \\
(21 \%)\end{array}$ & $\begin{array}{c}9 \\
(11 \cdot 8 \%)\end{array}$ & $\begin{array}{c}9 \\
(11 \cdot 8 \%)\end{array}$ & $\begin{array}{c}10 \\
(13 \cdot 2 \%)\end{array}$ & $\begin{array}{c}8 \\
(10 \cdot 6 \%)\end{array}$ & $\begin{array}{c}4.3 \%) \\
(2 \cdot 7 \%)\end{array}$ & Nil \\
\hline
\end{tabular}


of observation for the men whose simple pneumoconiosis remained unchanged were $10 \cdot 1$ years for the gastrectomy group, 10.4 years for the gastroenterostomy group, 8.8 years for the perforated ulcer group, and 13.2 years for the control series. However, even if the attack rates of the gastroenterostomy and perforation groups were increased by half as much, they would still be lower than that of the partial gastrectomy group and this factor alone would be unlikely to account for the differences observed. There was probably no great difference between the various groups in relation to age, periods worked on the coal face, and the dates of observation. All men had either worked under approved dust conditions or had left the industry since certification. Thus it would appear that, for some reason as yet unknown, the risk of developing PMF in men with simple pneumoconiosis is greater after partial gastrectomy than after either gastroenterostomy or perforation.

Simple pneumoconiosis is due to the inhalation of dust alone (Gough, 1947), but an additional factor is required to explain the occurrence of PMF (Gough, 1960; Duguid and Lambert, 1964). This has often been regarded as tuberculosis (Belt and Ferris, 1942; Fletcher, 1948; Heppleston, 1951; Cochrane, 1954; Fletcher, 1955; Nethercott and Strawbridge, 1956; Gough, 1960) and this is supported by the fact that the location of the lesions in the lung and their subsequent spread is similar to that of tuberculosis (Higgins, 1957; O'Neill and Robin, 1964). In addition, published series of necropsies on men with PMF have shown a high percentage (30 to $60 \%$ ) of cases in which tubercle bacilli have been found (James, 1954; Rivers, James, Davies, and Thomson, 1957). Nodular lesions have also been produced experimentally in animals by the combined injection of various dusts mixed with tubercle bacilli (King, Yoganathan, Harrison, and Mitchison, 1957), although similar lesions have been produced experimentally by using dead bacilli (Attygalle, Harrison, King, and Mohanty, 1954). The development of PMF has also been ascribed to atypical mycobacterial infection, notably by Mycobacterium kansasii and $M$. avium in some cases (Gernez-Rieux, Tacquet, Voisin, and Devulder, 1965). However, Cochrane (1962) did not find any association between the attack rate of PMF and either exogenous or endogenous tuberculous infection, although he discovered that the attack rate depended on the background of simple pneumoconiosis present, being zero for category half and rising to $30 \%$ for category 3 over the eight-year period of his survey. In addition, Hart, Cochrane, and Higgins (1963) found no difference in tuberculin skin sensitivity between men with PMF and those with either simple pneumoconiosis or no pneumoconiosis at all. There is also no doubt that there are many men with PMF in whom it is not possible to establish the presence of tuberculosis definitely by skin tests, sputum cultures or even post-mortem examination (James, 1954; Rogers, 1946; Gooding, 1946). While tuberculosis may lead to PMF in some cases, there is little doubt that there may be other causes.

An immunological mechanism for explaining the development of PMF in silicosis has been suggested (Vigliani and Pernis, 1958; Webster, Palmhert, Cooper, Silverton, Anderson, Zoutendyk, and McNab, 1960; Pernis, 1963). The theory is that silica enters the macrophages and damages them, with the liberation of antigenic substances, which lead to the production of antibodies in some subjects, which precipitate in the form of a hyaline substance. It has also been suggested that this mechanism may occur in coal workers' pneumoconiosis, and this hypothesis is supported by the association shown to exist between rheumatoid arthritis, an accepted auto-immune disease, and the development of a distinctive nodular type of massive fibrosis (Caplan, 1953; Caplan, Payne, and Withey, 1962). Lindars and Davies (1967) suggested that both the quantity of dust in the lungs (which increases with the category of simple pneumoconiosis present (Rivers, Wise, King and Nagelschmidt, 1960) and the immune response of the individual may be involved in the aetiology of PMF. Complicated pneumoconiosis has also been shown to be associated with an abnormal pattern of iron metabolism, with a low serum iron and total iron binding capacity (TIBC) in seropositive (Rose Waaler titre over 1:32) cases and a low TIBC in seronegative cases (Chan, 1969). In contrast, a low serum iron level with a raised TIBC may be expected after partial gastrectomy (Turnbull, 1965; Wallensten, 1955).

The immunological status of the men in the present series was not investigated, but in view of the high rate of tuberculosis in the partial gastrectomy group, I suggest that PMF in some of these men may have been started by a sub-clinical tuberculous infection. Because of the small number of men with simple pneumoconiosis read as category 3 in this series, it was not felt that any conclusions could be drawn about any increased likelihood of this category to progress to PMF.

Simple pneumoconiosis is not in itself a cause of disability or early death (Gilson, 1963). The disability due to pneumoconiosis has been shown to be related to the area of PMF and the background on the chest radiograph (Cochrane, Moore, and Thomas, 1961; Cochrane and Higgins, 1961). It is therefore important to reduce the possibility of the development of PMF in men with simple pneumoconiosis. Both partical gastrectomy and vagotomy with gastro-enterostomy or other form of drainage 
operation are established procedures in the elective treatment of duodenal ulcer, and the difference in results is small (Goligher, Pulvertaft, and Watkinson, 1964: Cox, 1968; Goligher, Pulvertaft, de Dombal, Clark, Conyers, Duthie, Feather, Latchmore, Matheson, Shoesmith, Smiddy, and Willson-Pepper, 1968). Because this study shows an increased incidence of active tuberculosis as well as a possible increase in the incidence of PMF following partial gastrectomy, it is recommended that this operation be avoided in the surgical treatment of peptic ulcer in coal miners with pneumoconiosis.

\section{References}

Allison, S. T. (1955). Pulmonary tuberculosis after subtotal gastrectomy. New Engl. J. Med., 252, 862-863.

Anderson, C. D., Gunn, R. T. S., and Watt, J. K. (1955). Results of partial gastrectomy in treatment of peptic ulcer. Brit. med.J., 1, 508-511.

Attygalle, D., Harrison, C. V., King, E. J., and Mohanty, G. P. (1954). Infective pneumoconiosis. I. The influence of dead tubercle bacilli (B.C.G.) on the dust lesions produced by anthracite, coal-mine dust, and kaolin in the lungs of rats and guinea pigs. Brit. J. industr. Med., 11, 245-259.

Balint, J. A. (1958). Pulmonary tuberculosis and partial gastrectomy. Gastroenterologia (Basel), 90, 65-84.

Bedford, T., and Warner, C. G. (1943). Chronic pulmonary diseases in South Wales Coal Miners. II-Environmental Studies. Spec. Rep. Ser. med. Res. Coun. (Lond.), No. 244, pp. 1-78. H.M.S.O., London.

Belt, T. H., and Ferris, A. A. (1942). Chronic pulmonary disease in South Wales coalminers. I. Medical Studies. C. Pathological Report. Spec. Rep. Ser. med. Res. Coun. (Lond.), No. 243, pp. 203-222. H.M.S.O., London.

Caplan, A. (1953). Certain unusual radiological appearances in the chest of coalminers suffering from rheumatoid arthritis. Thorax, 8, 29-37.

, Payne, R. B., and Withey, J. L. (1962). A broader concept of Caplan's syndrome related to rheumatoid factors. Thorax, 17, 205-212.

Chan, B. W. B. (1969). Serum iron and iron kinetics in coalworkers with complicated pneumoconiosis. Brit.J. industr. Med., 26, 65-70.

Cochrane, A. L. (1954). Tuberculosis and coalworkers' pneumoconiosis. Brit. J. Tuberc., 48, 274-285.

- (1962). The attack rate of progressive massive fibrosis. Brit. J. industr. Med., 19, 52-64.

- Moore, F. and Thomas J. (1961). The prognostic value of radiological classification in cases of progressive massive fibrosis. Tubercle (Lond.), 42, 64-71.

, and Higgins, I. T. T. (1961). Pulmonary ventilatory functions of coalminers in various areas in relation to the X-ray category of pneumoconiosis. Brit. J. prev. soc. Med., 15, 1-11.

Cox, A. G. (1968). Comparison of symptoms after vagotomy with gastrojejunostomy and partial gastrectomy. Brit. med. J., 1, 288-290.

Duguid, J. B., and Lambert, M. W. (1964). The pathogenesis of coal miner's pneumoconiosis. J. Path. Bact., 88, 389-403.

Fletcher, C. M. (1955). Epidemiological studies of coal miners' pneumoconiosis in Great Britain. Arch. industr. Hlth, 11, 29-41.

(1948) Pneumoconiosis of coal-miners. Brit. med. J., 1, 10151022.

Gernez-Rieux, C., Tacquet, A., Voisin, C., and Devulder, B. (1965). Le rôle des infections dans la pathogénie des fibroses massives progressives des mineurs de charbon. Med. d. Lavoro, 56, 500-516.

Gilson, J. C. (1963). Mineral Dust in Industry, pp. 44-56. H.M.S.O., London.

Goligher, J. C., Pulvertaft, C. N., and Watkinson, G. (1964). Controlled trial of vagotomy and gastro-enterostomy, vagotomy and antrectomy, and subtotal gastrectomy in elective treatment of duodenal ulcer: interim report. Brit. med. J., 1, 455-460. , - , de Dombal, F. T., Clark, C. G., Conyers, J. H., Duthie, H. L. Feather, D. B., Latchmore, A. J. C., Matheson, T. S.,
Shoesmith, J. H., Smiddy, F. G., and Willson-Pepper, J. (1968). Clinical comparison of vagotomy and pyloroplasty with other forms of elective surgery for duodenal ulcer. Brit. med. J., 2 , 787-789.

Gooding, C. G. (1946). Pneumoconiosis in South Wales anthracite miners. Lancet, 2, 891-896.

Gough, J. (1947). Pneumoconiosis in coal workers in Wales. Occup. Med., 4, 86-97.

(1960). Pneumoconiosis and infection. In Proceedings of the Pneumoconiosis Conference of the South African Council for Scientific \& Industrial Research, Johannesburg, 1959, pp. 322-324. Edited by A. J. Orenstein. Churchill, London.

Hart, J. T., Cochrane, A. L., and Higgins, I. T. T. (1963). Tuberculin sensitivity in coal workers' pneumoconiosis. Tubercle (Lond.), 44, 141-152.

Heppleston, A. G. (1951). Coal workers' pneumoconiosis. Pathological and etiological considerations. Arch. industr. Hyg., 4, 270-288.

Higgins, I. T. T. (1957). Tuberculosis and progressive massive fibrosis. Tubercle (Lond.), 38, 123-125.

International Labour Organization (1959). Meeting of experts on the international classification of radiographs of the pneumoconiosis. Occup. Safety Hlth, 9, 63-69.

James, W. R. L. (1954). The relationship of tuberculosis to the development of massive pneumoconiosis in coal workers. Brit. J. Tuberc., 48, 89-96.

King, E. J., Yoganathan, M., Harrison, C. V., and Mitchison, D. A. (1957). Experimental infective pneumoconiosis. Arch. industr. Hlth, 16, 380-392.

Levij, I. S., and La Fuente, A. A. de (1963). A post mortem study of gastric and duodenal peptic lesions. Gut, 4, 349-359.

Lindars, D. C., and Davies, D. (1967). Rheumatoid pneumoconiosis: a study in colliery populations in the East Midlands coalfield. Thorax, 22, 525-532.

National Coal Board (1965). The sampling of airborne dust for the testing of approved dust conditions (Report F. 3837). pp. 3-5 (London).

Nethercott, S. E., and Strawbridge, W. G. (1956). Infective nature of massive pneumoconiosis. Brit. med. J., 1, 1361.

O'Neill, R. P., and Robin, E. D. (1964). Relations of pneumoconiosis and pulmonary tuberculosis. Arch. environm. Hlth, 8, 873-881.

Pearson R. S. B. (1954). Pulmonary tuberculosis following partial gastrectomy. Postgrad. med. J., 30, 159-162.

Pernis, B. (1963). Immunohistochemical observations on the human silicotic nodule. Med. $d$. Lavoro, 54, 354-363.

Pulvertaft, C. N. (1964). The late results of gastric resection. Brit. J. Surg., 51, 414-419.

Rivers, D., Wise, M. E., King, E. J., and Nagelschmidt, G. (1960). Dust content, radiology, and pathology in simple pneumoconiosis of coalworkers. Brit. J. industr. Med., 17, 87-108.

- James, W. R. L., Davies, D. G., and Thomson, S. (1957). The prevalence of tuberculosis at necropsy in progressive massive fibrosis of coalworkers Brit. J. industr. Med., 14, 39-42.

Rogers, E. (1946). Pneumoconiosis in South Wales coalmines. Lancet, 1, 462.

Thorn, P. A., Brookes, V. S., and Waterhouse, J. A. H. (1956). Peptic ulcer partial gastrectomy, and pulmonary tuberculosis. Brit. med. J., 1, 603-608.

Turnbull, A. L. (1965). The absorption of radioiron given with a standard meal after Polya partial gastrectomy. Clin. Sci., 28, 499-509.

Vigliani, E. C., and Pernis, B. (1958). Immunological factors in the pathogenesis of the hyaline tissue of silicosis. Brit.J. industr. Med., 15, 8-14.

Wallensten, $S$. (1955). The relation between sideropenia and anemia and the occurrence of postcibal symptoms following partial gastrectomy for peptic ulcer. Surgery, 38, 289-297.

Warthin, T. A. (1953). Reactivation of pulmonary tuberculosis in relation to subtotal gastrectomy for peptic ulcer. Amer. J. Med. Sci., 225, 421-426.

Webster, I., Palmhert, H., Cooper, D. R., Silverton, R. E., Anderson, C. S., Zoutendyk, A., and McNab, G. (1960). The immunological approach to silicosis. In Proceedings of the Pneumoconiosis Conference of the South African Council for Scientific and Industrial Research. Johannesburg, 1959. Edited by A. J. Orenstein, pp. 408417. Churchill, London.

Received for publication September 5, 1969. 